\title{
EULER: VANGUARDISMO E GENIALIDADE PARA ALÉM DO SÉCULO XVIII
}

\author{
Daniele Esteves Pereira ${ }^{1}$ \\ Secretaria de Educação do Estado do Pará
}

\section{RESUMO}

Leonhard Paul Euler (1707 - 1783), ou apenas Euler, é como o matemático, filósofo e físico suíço gravara seu nome na história das ciências, marcando-a com sua genialidade e vanguardismo. Estas duas características marcantes da trajetória de Euler, instigaramnos a revisitar o século XVIII, para pontuar a extensão, a complexidade, a ousadia e a criatividade dos trabalhos de um das mais importantes personalidades da história das ciências da era moderna. O presente artigo desenvolveu-se a partir de uma abordagem abreviada sobre certos aspectos de sua trajetória de vida, com o intuito de relacionar com sua vasta produção científico-cultural no período Iluminista europeu, com destaque aos seus trabalhos que mais contribuíram para a construção do conhecimento físicomatemático.

Palavras-Chave: História da Matemática. Leonhard Euler. Produção CientíficoCultural.

\section{De Basel para o mundo}

Leonhard Paul Euler nasceu na cidade de Basel, norte da Suíça, fronteira entre a França e Alemanha, em 15 de abril de 1707. Tivera a vida marcada por sua genialidade e vanguardismo. Produziu mais de 400 obras complementares e, até o ano de 1783, sua produção era composta 866 trabalhos. $^{2}$

Figura 01 - Mapa político da Suíça no século XVIII

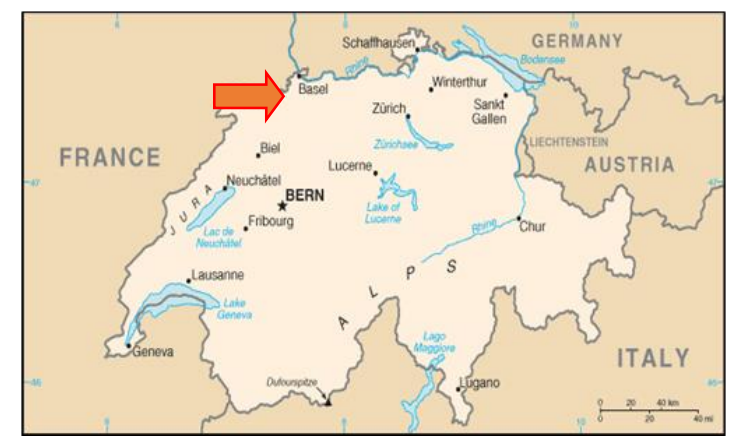

Fonte: Série História em revista

\footnotetext{
1 danieleyz@gmail.com

2 A totalidade das obras de Euler encontram-se catalogadas no Índice de Eneström produzido pelo historiador matemático Gustav Eneström $(1856-1923)$ e disponibilizadas no site http://www.math.dartmouth.edu/ euler/index/enestrom.html. (D’AMBROSIO, 2009)
} 
Apesar da importância científica de Euler ser estendida a toda Europa, com participações em várias academias de diferentes países (Académie Royale des Sciences de Paris, Royal Society of London e Società Scientifica Privata Torinese), sua história de vida pode ser concentrada em três núcleos, a saber: a infância e adolescência nos primeiros vinte anos em Basel na Suíça (1707-1727), duas fases em São Petersburgo na Rússia; a juventude (1727-1741) e o retorno até seus últimos dias (1766-1783), além do período em Berlim na Prússia (1741-1766). D’Ambrosio (2009) esclarece que a instabilidade de Euler nos centros urbanos e academias estava relacionada ao irrequieto momento político europeu, à medida que as nacionalidades começavam a formar seus territórios.

Figura 02 - Leonhard Euler

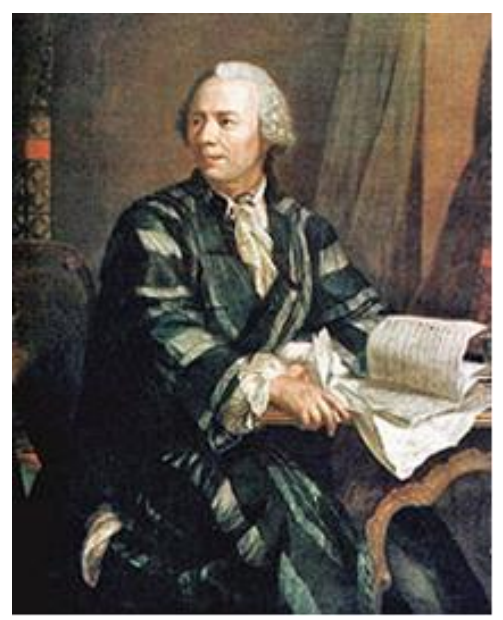

Fonte: www.eulerarchive.com

Uma síntese sobre a grandeza dos trabalhos de Euler para o século XVIII e da importância do seu legado para o progresso de vários ramos da ciência é traduzida com muita propriedade pelas palavras de Guilherme de La Penha (1983, p. 1)

Euler exibiu cada uma das qualidades exaltadas por um matemático.
Absorveu e expandiu todos os ramos que eram cultivados em seu tempo;
trouxe de volta à vida assuntos antigos e negligenciados e traçou novos
cursos de pensamento que vieram a florescer em séculos posteriores.
Resolveu muitos problemas especiais famosos; combinou e relacionou teorias
anteriormente distanciadas; criou novos conceitos; mais que qualquer outro
homem, organizou disciplinas inteiras de uma forma tão clara e simples que
por séculos elas eram ensinadas à sua maneira, como algumas ainda o são até
hoje.

A influência da vida intelectual de Euler transpassou o século XVIII e permanece até a atualidade com suas contribuições de forma indelével na matemática, 
física e engenharias. Em consequência a consistência, extensão e profundidade das atividades acadêmico-científicas do matemático. (PEREIRA, 2014).

O Ginásio de Basel foi sua primeira escola, instituição que não continha matemática em seu desenho curricular. Por este motivo as primeiras noções das disciplinas foram ministradas pelo pai e primeiro instrutor, Paulus Euler. Passou a estudar sozinho diversos textos e a tomar lições particulares em casa. Embora, seu pai o tenha instruído primeiramente, desconsiderou sua extraordinária inclinação matemática e determinou que o filho estudasse filosofia e seguir a mesma carreira religiosa. (LA PENHA, 1983, p. 2).

Paulus Euler era amigo da família Bernoulli, e tivera Jakob Bernoulli (1655 1705) como seu ex-professor. Posteriormente, seu irmão Johann I Bernoulli (1667 1748), um dos matemáticos mais importantes da Europa, tornara-se tutor de Euler.

A instrução formal de Euler avançou com a chegada de sua adolescência, quando retornara à sua cidade natal para morar com a avó e estudar, preparando-se para o curso de teologia da universidade local. Aos 13 anos de idade matriculou-se na Universidade de Basel e, desde então, tornara-se o discípulo favorito de Johann I Bernoulli que rapidamente descobriu o seu talento para a matemática e passou a instruílo juntamente com seu filho Daniel I Bernoulli (1700-1782).

Neste período, o jovem estudava teologia, grego e hebreu, seguindo as orientações de pai para se tornar um futuro pastor. Embora muito religioso não se entusiasmou com os estudos teológicos. Assim, Johann Bernoulli resolveu intervir e convenceu Paul Euler de que o seu filho estava destinado a ser um grande matemático. Em 1723, aos 16 anos, recebera o grau de mestre, com uma tese comparando as filosofias de Descartes e de Newton. (D’AMBROSIO, 2009).

Com este trabalho sobre o som Euler concorrera a uma cadeira de física na Universidade de Basiléia. O estudo foi bem recebido, mas Euler não chegou a ser contratado como professor, provavelmente por ter apenas 19 anos, o que o levaria, posteriormente a emigrar para a Rússia. Calinger (1995) sugere esta decisão contribuiu para que o jovem matemático deixasse sua pequena república para trabalhar em um espaço mais propício para suas pesquisas e conviver com um selecionado grupo de físico-matemáticos da época. 
Euler recebeu menção honrosa por sua participação em um concurso promovido pela Academia de Ciência de Paris, com o trabalho sobre o melhor posicionamento de mastros de um navio intitulado de Meditationes super problemate náutico (Reflexões sobre um problema náutico. O primeiro lugar foi atribuído a Pierre Bouguer (1698 1758), participante de uma expedição à América do Sul, que ficaria conhecido mais tarde como o pai da arquitetura naval. Naquele período, os prêmios como o da Academia francesa, constituíam a principal honraria científica do século e representavam uma quantia monetária substancial. "Dentre os agraciados, Johann Bernoulli ganhou duas vezes, seu filho Daniel Bernoulli recebeu-o dez vezes e Euler conquistou-o doze vezes, correspondendo um prêmio por cada quatro anos de sua vida como matemático (CHAQUIAM, 2012, p. 212).

\section{Uma parada em São Petersburgo}

Em 1727, após o falecimento de Pedro I, Czar de todas as Rússias (1672 - 1725) Catarina I (1684 - 1727), sua viúva ascendera ao poder, permanecendo por apenas dois anos. Daniel e Niklaus II Bernoulli (1695 - 1726), então integrantes da academia russa, sugestionaram a czarina o nome de Euler para assumir o posto de estudante de Fisiologia (associado) na Academia de Ciências de São Petersburgo (LA PENHA, 1983, p. 3). Como não fora selecionado para a cadeira de física da Universidade de Basel, aceitou o convite, mudando-se para a Rússia, onde estreitou contatos com outros cientistas como o analista e geômetra Jakob Hermann (1678 - 1733), o amigo próximo Daniel Bernoulli com quem tinha interesses em comum no campo da matemática aplicada, Christian Goldbach (1690 - 1764) com quem discutiu diversos problemas de análise e teoria dos números, o astrônomo e geógrafo Joseph-Nicolas Delisle (1688 1768), entre muitos outros (FIOLHAIS, 2008).

A distância percorrida entre os dois países foi alcançada por uma longa viagem em que Euler dedicou-se intensamente aos estudos para poder assumir sua nova função. No decorrer do trajeto, o matemático fez uma parada em Marburgo, local em que encontrou Chistian Wolff (1679 - 1754), influente personalidade por ser alvo central de disputas teóricas entre Newton e Leibniz ${ }^{3}$ e, assessor do czar no projeto de construção

\footnotetext{
${ }^{3}$ A disputa entre Newton e Leibniz sobre a primazia na criação do cálculo infinitesimal foi seguida por uma polêmica sobre o lugar de Deus do mundo "havia enorme diferença entre o Deus diligente de Newton, que vinha a intervir amiúde no mundo para efetuar algumas correções, e o Deus preguiçoso de
} 
da Academia de São Petersburgo. Contudo, sua chegada e posterior contratação acabaram sendo tumultuadas pelos funerais de Catarina I.

A Academia de São Petersburgo foi desenvolvida com a finalidade de elevar a qualidade da educação no país e preencher a lacuna existente no campo das ciências quando comparado ao nível da Europa Ocidental. Para tanto, ficou determinado que para alcançar tais objetivos dever-se-ia incentivar o intercâmbio com estudiosos de outros países europeus.

Todavia, os novos dirigentes responsáveis pela academia russa não eram favoráveis à contratação de estrangeiros e à continuidade do processo de modernização, acirrando-se com isso conflitos entre os europeus e as divergências de correntes teóricas (Newton Descartes e Leibniz). Euler tornou-se professor de Física na Academia em 1730.

O panorama emergente dessa outra configuração política brindou Euler com a transferência para a seção de Matemática, onde efetivou-se professor em 1733, cargo deixado pelo retorno dos irmãos Bernoulli à Suíça.

Durante sua estadia no país, o matemático compartilhou com seu amigo Daniel Bernoulli a moradia e diversos trabalhos. Habituou-se tanto a vida em São Petersburgo que se propôs a dominar a língua russa, além do que aceitou nos primeiros anos de sua chegada um trabalho adicional de médico-tenente na Marinha Russa de 1727 a 1730.

O enfoque da produção científica de Euler após 1730 foi a cartografia, o magnetismo, os motores a combustão, as máquinas e a construção naval. Suas pesquisas na área da matemática centravam-se na teoria de números, nas análises no infinito, nas equações diferenciais, no cálculo de variações e, na mecânica racional.

\footnotetext{
Sua permanência na Rússia foi um período de grande produtividade. Dentre os inúmeros trabalhos que publicou, destacam-se: em 1736, um tratado de mecânica analítica, em 2 volumes, Mechanica sive motus scientia analytice exposita; em 1738-40, uma Introdução à Arte da Aritmética para Uso nas Escolas Elementares Afiliadas à Academia Imperial de São Petersburgo, em 2 volumes; em 1739, uma Teoria da Música, Tentamen novae theoriae musicae. (D’AMBROSIO, 2009, p. 22).
}

Leibniz, que descansava para sempre depois de ter feito o trabalho inicial de criação!" (FIOLHAIS, 2009, p.5). Essas disputas impediram que tivesse ocorrido antes uma síntese entre as duas formas de cálculo que, no fundo, eram confluentes. 
Figura 03 - Frontispício dos livros Mechanica sive motus scientia analytice exposita e Tentamen novae theoriae musicae, respectivavemente
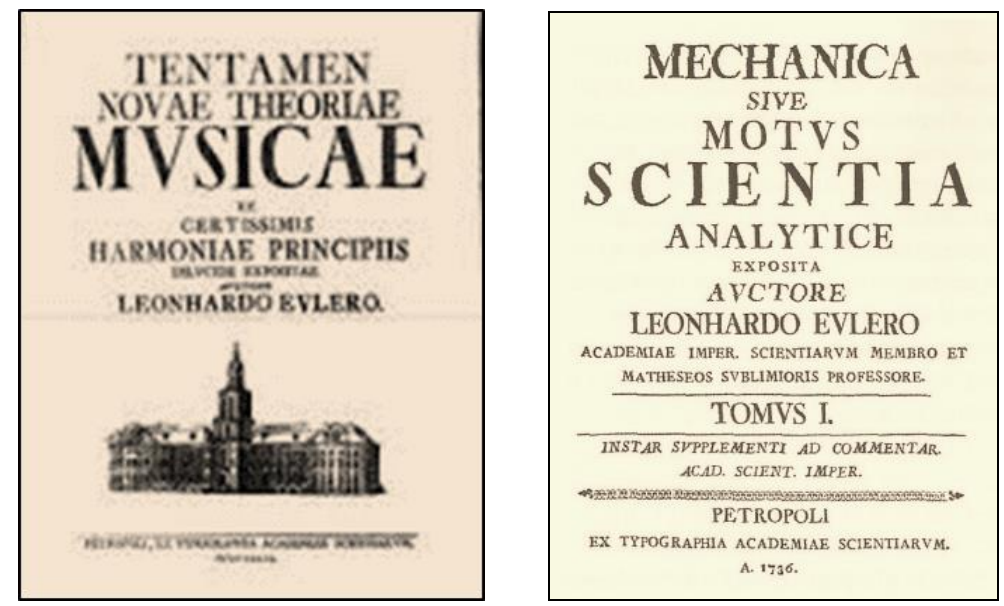

Fonte: www.openlibrary.org.

A partir de 1735 o matemático consolidou sua carreira, alcançando notoriedade em todo o mundo. Um destes trabalhos foi o desenvolvimento de um método analítico para resolver o conhecido Problema de Basel sobre a soma da série infinita dos inversos dos quadrados. A solução deste problema era um desafio para matemáticos de todo o globo e, particularmente Johann Bernoulli dedicara décadas de seus estudos na busca de uma solução, sem, no entanto, lograr êxito.

Outro destaque da sua vida científica foi a conquista por duas vezes do Grande Prêmio da Academia de Paris em 1738 e 1740. Nas duas oportunidades, Euler dividiu o primeiro prêmio com outros matemáticos.

\section{A monarquia prussiana}

O reconhecimento dos trabalhos de Euler abriram-lhe as portas de Berlim por meio de um convite de Frederico II para trabalhar na Academia de Ciências da Prússia. Inicialmente, declinou ao convite por preferir permanecer em São Petersburgo. Entretanto, o momento político na Rússia era desfavorável devido à disputa pela sucessão do trono após a morte de Catarina I. Desse modo, em 1741, partiu para viver em Berlim com sua família, onde vivera por 25 anos e produzira mais de 380 publicações, entre elas as duas que lhe promoveriam mais reconhecimento, em 1748, Introductio in analysin infinitorum, e Institutiones calculi differentialis de 1755. 
O contexto no qual Euler é inserido na sua chegada à Berlim é o de que o rei Frederico II ascendera ao trono prussiano a cerca de um ano atrás. A Sociedade de Cientistas Berlim-Brandenburgo, fundada em 1700 tivera Leibniz na sua presidência. Frederico II decide modernizá-la inspirado no modelo da Academia de Ciências de Paris. Para tanto, convidou cientistas renomados para compor o quadro de remodelação, entre estes Pierre-Louis Moreau de Maupertuis (1698-1759), que tornara-se o primeiro presidente da Académie Royale des Sciences et Belles Lettres (Real Academia de Ciências e Belas Letras), inaugurada oficialmente em 1744 e Euler, como diretor da seção de matemática. O monarca solicitou à Euler que suas pesquisas se concentrassem em atividades técnicas, direcionadas à área militar e bélica.

Euler integrou-se às funções da nova academia intensamente, com a supervisão do observatório e o jardim botânico, selecionando recursos humanos, e a gerência de vários aspectos financeiros. Fez parte do comitê da Academia e assumiu ainda a coordenação da publicação de mapas geográficos, uma fonte de recursos para a Academia, e a publicação de trabalhos científicos, aumentando consideravelmente sua própria produção científica com livros bastante populares na Europa.

A produção de Euler envolvia livros sobre cálculo de variações e órbitas dos planetas, artilharia e balística, construção naval e navegação, sobre o movimento da Lua, cálculo diferencial e Lettres à une Princesse d'Allemagne sur divers sujets de physique et de philosophie (Cartas a uma princesa da Alemanha sobre diversos temas de física e filosofia), obra escrita sob a forma epistolar que se tornaria um best-seller imediato na Europa e, que por muito tempo permaneceram como a sinopse mais amplamente distribuída sobre a cultura científica e filosófica popular do período. (FELMANN, 2007, p.73 tradução livre). 
Figura 04 - Frontispício do livro original Lettres à une princesse d'Allemagne sur divers sujets de physique \& de philosophie. Saint-Pétersbourg: Imprimerie de l'Académie impériale des Sciences, (1768-1772).

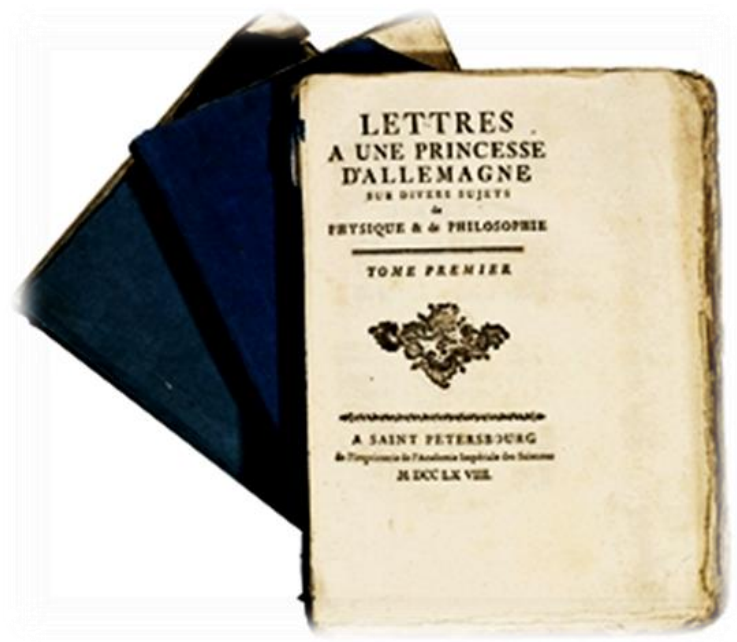

Fonte: www.christies.com

As importantes contribuições de Euler para a Academia de Berlim e, consequentemente sua consolidação como uma instituição de prestígio no continente europeu não foram suficientes para sustentar a permanência do matemático no país. Maupertius (1698 - 1759) teve seus princípios diretamente confrontados pelo filósofo francês Voltaire (1694 - 1778), amigo pessoal de Frederico II. Euler possuía afinidades filosóficas com Maupertius. D'Ambrosio (2009) assinala que talvez essa aproximação tenha comprometido as relações entre Euler e Frederico II.

\section{O retorno à São Petersburgo}

A imperatriz Catarina II, a Grande, acendeu ao trono russo em 1762. Logo, dedicou-se a restabelecer o elevado padrão da Academia da Rússia. Lança um convite de retorno a Euler com vários privilégios, incluindo altos salários, auxílio moradia e cargos para seus filhos.

Em 1766, Euler voltou para a Rússia com muitas honrarias e prosseguiu seu árduo trabalho científico, sem diminuir a intensidade de sua produção. Logo, em 1768 lança o livro Institutiones Calculo Integralis (Fundamentos do Cálculo Integral).

O comprometimento com uma visão devido à experiências realizadas no campo da Óptica, não interferiu sua rotina de trabalho. Pelo contrário, passou a defender a 
teoria ondulatória da luz, de autoria do holandês Christiaan Huygens (1629-1695). Ao perder totalmente sua visão, Euler considerava-se privilegiado por não ter maiores distrações. Em 1772, publicou um livro sobre o movimento da lua intitulado de Theoria Motuum Lunae (Teoria do movimento da Lua).

Em 1771, a cidade de São Petersburgo foi tomada por um grande incêndio que atingiu a casa de Euler e, devido sua relutância em deixar a residência conseguiu salvar todos os seus manuscritos.

\section{Considerações finais}

Euler faleceu subitamente aos 77 anos em São Petersburgo. Neste momento havia sido contratado para escrever um tratado sobre hidromecânica em que o tratamento do assunto teria sido completamente reformulado.

Suas obras revelam contribuições significativas no âmbito da matemática entre os quais cálculos, gráficos, análises, terminologia e notação da matemática moderna, como a noção de uma função matemática. Pela extensão e diversificação de seus trabalhos científicos, o nome de Euler aparece na literatura matemática associado a várias invenções, teoremas e fórmulas como a Fórmula de Euler do poliedro e o Problema das 07 pontes de Königsberg, entre outras.

Na Física, reformulou a dinâmica Newtoniana e definiu a fundação da mecânica analítica, especialmente na sua Teoria dos Movimentos de Corpos Rígidos. Em parceria com o seu professor Johann Bernoulli, elaborou a mecânica contínua e realizou trabalhos com a teoria cinética de gases com o modelo molecular. Na companhia de Alexis Clairaut (1713-1765) estudou a teoria lunar. Fez ainda pesquisa fundamental em elasticidade, acústica, a teoria de onda de luz, e o hidromecânica de navios, além de muitos outros.

O matemático e físico deixou como seu legado uma produção científica notável. Expôs muitas qualidades exaltadas para as funções que exercia. Absorveu e ampliou todos os segmentos que eram explorados em seu tempo. Fez emergir assuntos antigos e esquecidos e traçou novos parâmetros de pensamento que vieram a progredir em séculos posteriores, os quais foram ao longo dos anos reconhecidos, enriquecidos de detalhes, acrescentados de provas e de novas estruturas organizacionais ao conjunto da obra, recebendo formas mais coesas. 
O dimensionamento da variedade suas obras pode ser conferido pela produção da Academia de Ciências de São Petersburgo que continuou a publicar trabalhos novos de Euler até 50 anos depois da sua morte.

Por fim, outros reconhecimentos também foram concedidos ao matemático e físico. Um encontra-se na cédula do franco-suíço, antes do euro virar a moeda no continente e, em 2002 o asteroide Euler foi batizado em sua homenagem.

\section{REFERÊNCIAS}

ALLAN, T. (Ed.) Poderes da coroa. Série História em revista. Trad. Pedro Maia Soares. Rio de Janeiro: Abril livros, 1992. (Série história em revista, v. 5, n. 1).

CHAQUIAM, M. Guilherme de La Penha: uma história do seu itinerário intelectual em três dimensões. Tese (Doutorado). Universidade Federal do Rio Grande do Norte. Centro de Educação. Programa de Pós-Graduação em Educação. Natal/RN, 2012, 284 f.

D'AMBROSIO, U. Euler, um matemático multifacetado. In: Revista Brasileira de História da Matemática - Vol. 9 n. 17 (abril/2009 -setembro/2009) - pág. 13-31.

EULER, L. Cartas a una princesa de Alemania sobre diversos temas de física y filosofia. Trad. Carlos Mínguez Pérez. Zaragoza: Universidad, Prensas Universitarias, 1990.

FELLMANN, E. A. Leonhard Euler. Trad. Erika Gautschi e Walter Gautschi. Basel, Suíça: Birkhäuser Verlag, 2007.

FIOLHAIS, C. O génio de Euler na matemática e na física. Disponível em: <http://www.estudogeral.sib.uc.pt>. Acesso em 2 dez. 2012.

LA PENHA, G. M. S. M. Leonardo Euler. Revista do Professor de Matemática, São Paulo, v. 3 n. 7. p. 1- 4, 1983.

PEREIRA, D. E. Correspondências científicas como uma relação didática entre história e ensino de matemática: o exemplo das cartas de Euler a uma princesa da Alemanha. Tese (Doutorado). Universidade Federal do Rio Grande do Norte. Centro de Educação. Programa de Pós-Graduação em Educação. Natal/RN, 2014, 276 f. 